\title{
Young adults' social drinking as explained by an augmented theory of planned behaviour: The roles of prototypes, willingness, and gender
}

\author{
Friederike Zimmermann* and Monika Sieverding \\ University of Heidelberg, Germany
}

\begin{abstract}
Objective. This study focused on young adults' alcohol consumption in social contexts. A dual-process model (including reasoned action and social reaction) was applied by combining the theory of planned behaviour (TPB) and the prototype/ willingness model. A key question was whether willingness and actor and abstainer prototype variables would augment the TPB by increasing explained variance.
\end{abstract}

Design. Participants completed questionnaires prior to spending an evening socializing over the weekend (Time I). Behavioural data were obtained by telephone interviews a few days after the social drinking occasion (Time 2).

Method. $N=300$ people (mean age 25 years) took part in the study. The outcome measure of pure alcohol in grams was calculated based on participants' reports about their consumed drinks. Multigroup path analyses were conducted because of sex differences on behavioural and psychological variables.

Results. The TPB explained $35 \%$ of the variance in men's and $41 \%$ in women's alcohol consumption. Augmentation with prototype perception and willingness contributed significantly to the prediction of intention $\left(\Delta R^{2}=.07\right)$ and alcohol consumption for men $\left(\Delta R^{2}=.14\right)$. A significant interaction implied that willingness led to heavy drinking particularly among those men who made negative evaluations of the abstainer prototype.

Conclusion. Women's alcohol consumption is explained by TPB variables via a more controlled reasoned-action path only, whereas additional processes (e.g., pursuing the actor image intentionally, rejecting the abstainer image more intuitively) are important for men. The moderating role of gender is discussed in light of traditional gender roles and recent trends in alcohol consumption.

One of the most problematic modes of alcohol consumption in young adults is risky drinking in single episodes, which typically takes place in social contexts during the weekend. This intake pattern is often referred to as binge drinking, and is common, for example, in the USA (Naimi et al., 2003) and in Europe (though to different extents in

* Correspondence should be addressed to Friederike Zimmermann, Psychological Institute, University of Heidelberg, Hauptstraße 47-5I, 69II 7 Heidelberg, Germany (e-mail: friederike.zimmermann@psychologie.uni-heidelberg.de). 
different countries, Gmel, Rehm, \& Kuntsche, 2003), and has mostly been studied in populations such as US college students (Wechsler, Lee, Kuo, \& Lee, 2000) or UK undergraduate students (Gill, 2002; Norman \& Conner, 2006). Recent evidence suggests that high episodic intake can be found among young adults (Bundeszentrale für gesundheitliche Aufklaerung, 2004) and university students (Bailer, Schwarz, Witthoeft, Stuebinger, \& Rist, 2008) in Germany as well. A range of adverse consequences has been related in particular to these drinking episodes; for example, drunk driving, unsafe sex, accidents, and furthermore, second-hand effects like being hit, or being a victim of sexual assault (Hingson, Heeren, Zakocs, Kopstein, \& Wechsler, 2002; Wechsler, Moeykens, Davenport, \& Castillo, 1995). The theory of planned behaviour (TPB), which is well-established in the field of health psychology, may present a useful basic framework for understanding alcohol consumption in emerging adulthood.

\section{The theory of planned behaviour}

The TPB is a social-cognitive theory for the explanation and prediction of intentional behaviour (Ajzen, 1991). Meta-analytic reviews have demonstrated the successful application of the TPB to a wide range of behaviours in general (Armitage \& Conner, 2001) as well as to health-related behaviours (Godin \& Kok, 1996). The variable that is posited as proximal to action is behavioural intention, which represents an individual's conscious decision to exert effort to perform the target behaviour. Behavioural intention, in turn, is a function of three belief-based constructs. Attitude towards the behaviour reflects the global positive or negative evaluation of performing the target behaviour. Subjective norm represents the target person's perception that significant others expect him or her to perform the behaviour. Perceived behavioural control (PBC) is the summary of perceived ease of performing or confidence in one's ability to perform the behaviour (i.e., self-efficacy, cf. Bandura, 1977) and whether control over the behaviour is up to the actor (Ajzen, 2002a; Trafimow, Sheeran, Conner, \& Finlay, 2002). Whereas the effects of attitude and subjective norm should be completely mediated by intention, $\mathrm{PBC}$ is also expected to influence behaviour directly (Ajzen, 1991).

Some studies have applied the TPB to alcohol use (e.g., Conner, Warren, Close, \& Sparks, 1999) and patterns of heavy episodic drinking (e.g., Johnston \& White, 2003; Norman, Bennett, \& Lewis, 1998). In line with meta-analyses that report only a minor role for the subjective norm within the TPB (see Conner \& Sparks, 2005) is the frequent failure of the subjective norm to predict intention as related to alcohol consumption (Collins \& Carey, 2007; McMillan \& Conner, 2003; Norman, Armitage, \& Quigley, 2007; Norman \& Conner, 2006; Wall, Hinson, \& McKee, 1998). Ajzen (1991) himself stated that the TPB was open to expansion. Its application to alcohol consumption may profit from a different social-cognitive approach that covers normative influences in the form of prototype perception.

\section{The self-prototype matching approach}

A prototype represents an object category since it possesses most of the category's features and few overlap with contrasting categories (Rosch \& Mervis, 1975). People have, for example, prototypes of person-in-situation categories, which contain knowledge of typical behaviours of typical people in particular settings (Cantor, Mischel, \& Schwartz, 1982). Health-risk behaviours are assumed to involve such clear images since they often take place in certain contexts and are associated with an identifiable group of people (e.g., 'cool people smoke cigarettes at a party'). A good 
representative of the group of people engaging in a particular behaviour (e.g., the 'typical smoker'), is termed the actor prototype. Two aspects of the prototype are usually investigated (sometimes multiplicatively combined): evaluation of the prototype and its similarity to the self-concept. Depending on the perceived un/favourability and dis/similarity, a person should be motivated to distance oneself from a prototype or to match it, respectively. The underlying mechanism is assumed to be the enhancement or the maintenance of self-consistency and a positive self (Dunning, Perie, \& Story, 1991; Niedenthal, Cantor, \& Kihlstrom, 1985).

Among adolescents, the perception of actor prototypes with respect to drinking alcohol was significantly related to current alcohol use and the intention to drink in the future (Chassin, Tetzloff, \& Hershey, 1985; Spijkerman, van den Eijnden, Vitale, \& Engels, 2004). Moreover, drinker prototypes predicted adolescents' drinking behaviour (Spijkerman, van den Eijnden, Overbeek, \& Engels, 2007), as well as the intention to drink and binge drinking behaviour among undergraduate students (Norman et al., 2007).

The typical person who refrains from a given behaviour - the abstainer prototype may also be influential, and was recently adopted in health psychology research. A few studies investigated the image of the type of person who abstains from alcohol use, and revealed its inhibiting influence on adolescents' intention to drink (Rivis, Sheeran, \& Armitage, 2006) and on their actual alcohol consumption (Gerrard et al., 2002).

\section{The prototype/willingness model}

Behaviour may be the result of a mostly deliberative process, and may be pursued intentionally as specified by the TPB (Ajzen, 1991). Health-risk behaviours are, however, often performed in social situations that present risk-conducive opportunities. People may then be willing to engage in a particular behaviour even if they have not previously intended to do so. Health-risk behaviour as a more spontaneous reaction to circumstances is incorporated by an additional route embedded in the prototype/ willingness model (PWM; Gibbons \& Gerrard, 1997; Gibbons, Gerrard, \& Lane, 2003). This dual-process model of behavioural determinants (cf. Fazio, 1990) integrates a social-reaction path involving more automatic processing, in addition to a more deliberative reasoned-action path via intention (Gibbons, Gerrard, Blanton, \& Russell, 1998; Gibbons et al., 2003).

The social-reaction path involves neither intention nor extensive deliberation, but rather, willingness to act in certain situations. Behavioural willingness reflects a person's openness to risk opportunities. It is the recognition that one might engage in a particular behaviour in reaction to a specific situation that arises. In contrast to intention, which typically involves pre-contemplation, willingness is comprised of responsiveness to the context in which predictors are relevant as more immediate influences (Gibbons, Gerrard, Ouelette, \& Burzette, 1998).

Another central element of the PWM is prototype perception. In the model, it is assumed that risk images influence only behavioural willingness (Gibbons et al., 2003). This is related to the original application of the model to adolescent health-risk behaviour (Gerrard, Gibbons, Houlihan, Stock, \& Pomery, 2008). Adolescents do not regard actor images related to alcohol use as fully positive (Chassin et al., 1985; Spijkerman et al., 2004). In such a case, it is unlikely that young people will be strongly motivated by the wish to acquire the attributes of, for example, 'a typical drinker' (cf. Gibbons \& Gerrard, 1995). Gerrard et al. (2002) investigated the actor and the abstainer 
prototypes with regard to drinking behaviour. They found that the favourable abstainer image represented a goal state for the American adolescents, whereas it was a question of relative favourability of the drinker image in association with willingness to accept it that was relevant for their behaviour. However, the situation may be more complex. While Rivis et al. (2006) found that perceived abstainer similarity had an inhibiting effect on the intention to drink in UK adolescents, they also found that similarity to the (on average very positive) actor image had a positive effect on the intention to drink.

Research has supported the independent dual-mode influences via willingness and intention (sometimes operationalized as expectation) on health-risk behaviour (e.g., alcohol use; Gerrard et al., 2006; Gibbons, Gerrard, Ouelette et al., 1998; Gibbons et al., 2004). The influence of risk images on willingness was demonstrated; drinker prototypes, for example, predicted drinking behaviour through willingness (Gerrard et al., 2002, 2006; Ouellette, Gerrard, Gibbons, \& Reis-Bergan, 1999).

\section{The present study}

We intended to investigate risky occasional drinking that is unaccounted for in global quantity-frequency measures of alcohol consumption (Stahre, Naimi, Brewer, \& Holt, 2006). Since detailed information on incidence rates and trends in Germany were not available, cognitive variables were assessed in relation to the lower limit of binge drinking (i.e., $\geq 4$ drinks in one session; Wechsler, Dowdall, Davenport, \& Rimm, 1995). Drinking more than three drinks (i.e., $36 \mathrm{~g}$ of pure alcohol given a content of $12 \mathrm{~g}$ per standard drink) clearly exceeds the harm-related tolerable amounts of daily alcohol intake for both sexes (British Medical Association, 1995; Corrao, Bagnardi, Zambon, \& La Vecchia, 2004; Robert Koch Institut, 2003). The outcome measure was not assessed by number of drinks consumed on one occasion due to definitional problems (Gmel et al., 2003), such as varying drink sizes: 'one' beer is by no means 'a standard drink', as $0.21,0.331,0.41,0.51$ are the usual quantities served in Germany; this is similar for wine, spirits, and liqueur. Instead, the dependent variable was the amount of pure alcohol consumed in grams during one evening of socializing. ${ }^{1}$

Variables from the PWM have predominantly been studied in American children and adolescents. We thought that the image associated with drinking/abstaining from alcohol and a more spontaneous reaction to the situation would be relevant for young adults' drinking in social contexts as well. Emergent young adults such as university students who are, for example, living away from their family homes, are in a different situation than children and adolescents whose drinking behaviour is restricted by law and parents (Dantzer, Wardle, Fuller, Pampalone, \& Steptoe, 2006). Drinking cultures may also be different across countries: whereas it is illegal to buy alcohol for those younger than 21 years in the USA, it is allowed to buy and drink spirits and drinks containing spirits from the age of 18 in Germany; adolescents are allowed to buy and drink beer and wine from the age of 16 , and are even allowed to drink these types of alcohol at the age of 14 when under supervision (e.g., with their parents). Thus, applied to emergent young German adults, the present study aims to make a twofold generalization of core features of the PWM.

\footnotetext{
${ }^{1}$ A cutoff value of $48 \mathrm{~g}$ was used to determine if $\geq 4$ drinks were consumed to allow for compatibility of questionnaire data and behavioural information, yielding, by and large, similar results to those reported. Men and women were not equally distributed in the binary outcome measure and since we had access to the more detailed information, we chose to report results for the continuous dependent variable.
} 


\section{Hypotheses}

The main question of the present study was whether willingness and perceptions of actor and abstainer prototype variables could successfully augment the TPB by explaining additional variance in alcohol consumption by young adults in social drinking contexts. The entire hypothetical model is composed of the following relationships (for an illustration cf. Figure 1a).

According to the TPB, a more positive attitude, a higher subjective norm, and higher PBC (represented by self-efficacy in this study) should result in higher intentions to drink several glasses of alcohol during an evening of socializing. As predicted by the PWM, attitude and subjective norm should as well influence behavioural willingness (Gibbons et al., 2003); we added self-efficacy as a further influence analogue to the TPB, because there was no reason to assume no impact on willingness.

Risk images are hypothesized as antecedents of willingness according to the PWM. We additionally expected the risk image to affect intention like in the prototype matching studies (e.g., Rivis et al., 2006). Hence, more positive evaluation and more similarity to the actor prototype should facilitate willingness and lead to higher intentions. Furthermore, we included the non-risk image and expected that more negative evaluation and less similarity to the abstainer prototype should facilitate willingness and lead to higher intentions.

The proximal determinants, intention and, willingness, form the dual-mode impact on alcohol consumption, complemented by the direct influence of self-efficacy. ${ }^{2}$ Finally, past behaviour, which is a good predictor of future behaviour, was controlled for to test the models' sufficiency (Ajzen, 1991, 2002b; Conner et al., 1999).

\section{Method}

\section{Sample and design}

Participants were $N=300$ young adults (153 male, 147 female; age: $M=24.7$, $S D=3.6$ years). Eighty per cent of the sample attended university and were engaged in diverse fields of study; $13 \%$ were employed, and $7 \%$ were in training or high school. Ninety-six per cent of the sample had a higher track secondary school certification (Abitur, i.e., the general qualification for the German university entrance).

The study design was prospective with two times of data collection. At Time 1, questionnaires were collected on Friday and Saturday afternoons in a cafeteria of the University of Heidelberg. Approximately, $80 \%$ of the people approached were willing to take part in the study and reported that they intended to spend one upcoming weekend evening socializing (i.e., probably had the opportunity to drink alcohol in a social context). Of 265 people who provided phone numbers or alternatively, e-mail addresses, 232 could be reached at Time 2 (203 by telephone, 29 by e-mail; $77 \%$ response rate).

Behavioural information was obtained a few days after the weekend drinking opportunity, mostly on Monday and Tuesday to minimize biases due to poor recall. Behavioural data were provided by 202 persons (101 male, 101 female) who were attainable at Time 2 and had actually spent a sociable evening over the weekend. Drop-out analyses indicated that there were no differences in socio-demographic or

\footnotetext{
${ }^{2}$ Although PBC was solely represented by self-efficacy in this study, its direct influence on behaviour was maintained (cf. Armitage, Conner, Loach, \& Willetts, 1999). According to Ajzen (199I) PBC should predict the target behaviour directly due to both aspects: (a) the confidence in mastering the behaviour and (b) the extent to which perceived control reflects actual control over the behaviour.
} 
psychological measures, except for subjective norm, which was higher among attainable people $(N=232 ; M=2.8, S D=1.9)$ versus not attainable $(N=68$; $M=2.2, S D=1.8), t(298)=2.21, p=.03$. Confidentiality was assured and contact information was destroyed following data entry.

\section{Measures}

Semi-structured interviews with an additional sample $(N=15)$ from the target population elicited beliefs, for example, positive and negative outcomes of drinking heavily during a sociable evening, and attributes describing the typical persons who would drink multiple alcoholic beverages or would only drink non-alcoholic drinks on such an occasion. Content analyses and review of the literature resulted in the initial measures, which were constructed in line with recommendations (Ajzen, 1991; Fishbein et al., 2001; Francis et al., 2004). The final questionnaire was derived after pretesting in an additional sample $(N=39)$ from the target population.

\section{Time I: Questionnaire}

The social-cognitive variables were phrased in relation to drinking several glasses $(>3)$ of alcohol during an evening of socializing. Unless otherwise stated, responses to items were on seven-point bipolar scales.

Behavioural intention directly followed the introduction about the target behaviour of drinking several glasses $(>3)$ of alcohol during an evening of socializing and was assessed by asking 'Do you intend to drink several glasses of alcohol tonight?' (no, in no case/yes, in any case). Attitude was assessed using seven semantic differential scales, covering both its more instrumental and more affective qualities: 'How is it for you to drink several glasses $(>3)$ of alcohol during an evening of socializing?' (pleasant/ unpleasant, harmful/beneficial [Ajzen, 2006; Norman et al., 2007], reasonable/unreasonable, sociable/unsociable, enjoyable/repulsive, relaxing/exhausting, turns on/ turns off [results of the elicitation procedure]). Reliability according to Cronbach's alpha was high $(\alpha=.85)$. The subjective norm was assessed by the item 'In my circle of friends it is expected of me that I drink several glasses $(>3)$ of alcohol during an evening of socializing' (strongly disagree/strongly agree). Two items measured self-efficacy with acceptable internal consistency $(\alpha=.62)$ : one semantic differential scale (easy/ difficult) and 'It is easy for me to drink several glasses $(>3)$ of alcohol during an evening of socializing' (strongly disagree/strongly agree).

The measure of behavioural willingness used in this study is a twofold adaptation. First, scenarios were created to elicit individual differences in openness to risk situations that involve young adults' drinking styles. Secondly, willingness was sensibly translated into German to preserve its meaning of being open to consume alcohol in the specific situation. Thus, it was not explicitly measured as 'how willing would you be to' (cf. Gerrard et al., 2006) because this would imply 'would you dare to' suggesting that one would have to achieve a goal. The two scenarios, designed to shift the focus of attention towards risk-conducive contexts, were introduced by: 'Imagine the following situations. You are out with some friends on a Saturday evening and have already consumed quite a number of alcoholic drinks. You have the impression that you drank enough'. (1) 'It is about midnight and someone having a birthday is paying for another round' (2) 'You are entering a flat-rate pub, that is, you can drink as much as you like after having paid the entrance fee'. Each scenario was followed by 'I continue drinking' (no, in no case/yes, in any case). The internal consistency was high $(\alpha=.86)$. 
A short definition built on the basis of Gibbons, Gerrard, and Boney-McCoy (1995) was given before measures of prototype perception were presented: 'The following questions concern your images of people. For example, we all have an image of what distinguishes the typical movie star ("rich and pretty") or the typical grandmother ("sweet and frail"). We all know, however, that not all movie stars or all grandmothers correspond exactly with these pictures - but many of them share some typical characteristics. Imagine now the typical person who consumes . . . ' . . . several $(<3)$ glasses of alcohol. . .' only non-alcoholic drinks ' . . during an evening of socializing'. In order to ensure that participants had clear images, they had to give ratings on 11 semantic differential scales: 'I think, such a person is in general': popular/unpopular (Gibbons \& Gerrard, 1995), responsible/irresponsible, willing to take risks/not willing to take risks, masculine/not masculine (adapted from Fishbein et al., 2001), feminine/not feminine (supplemented rationally), reasonable/unreasonable, sociable/ unsociable, easy/uptight, open/reserved, health-conscious/not health-conscious, able to enjoy/unable to enjoy (results of the elicitation procedure).

Following each prototype's activation, participants gave their evaluation of the image using a 0- to 100-point scale (cf. Haddock \& Zanna, 1994): 'How do you evaluate, all in all, this type of person, who drinks several $(<3)$ glasses of alcohol/only nonalcoholic drinks during an evening of socializing from 0 (extremely unfavourable) to 100 (extremely favourable)?'. Then, prototype similarity was rated by the response to 'How similar are you in general to this type of person?' (not at all similar/very similar). Two versions of the questionnaire were created alternating the order of actor and abstainer prototype variables.

Past behaviour was assessed with the item: 'Please think about the past 4 weeks for a moment. How many times did you drink several glasses $(>3)$ of alcohol during an evening of socializing?' Finally, basic socio-demographic data were requested.

Time 2: Interview

We asked participants to recall all alcoholic beverages they had consumed on that weekend evening and to specify the amount of each drink. Specifically, we asked them: 'What did you drink and how much of it?', followed by a coding scheme of different types of alcohol (e.g., beer, wine, spirits, liqueur, alcopop) and the typically served drink sizes (in $\mathrm{ml}$ ) with an additional open response format to cover different drinks and sizes; the number of each of the consumed drinks was recorded. We then calculated the total amount of pure alcohol consumed in grams during one evening of socializing for each person by summing the products of number of drinks of one type of alcohol $\times$ amount in $\mathrm{ml} \times$ per cent by volume $\times$ specific gravity of ethanol. The last question was about the duration of the drinking episode (in hours).

Reported quantities may be lower in telephone interviews than in self-administered questionnaires (Kraus \& Augustin, 2001), or e-mails. Hence, we tested whether the reported quantities at Time 2 differed as a function of assessment method: there was no difference in alcohol consumption between the assessment conditions of telephone $(N=175)$ versus e-mail $(N=27), t(200)=1.23, p=.22$.

\section{Data analyses}

The full model (TPB and PWM combined + past behaviour) and a more parsimonious model (TPB + past behaviour) were analysed by means of a path analysis in Mplus 
(Muthén \& Muthén, 2008). We conducted multigroup path analyses for women versus men to account for the significant sex differences that emerged in psychological and behavioural data (see Table 1). To explore whether significant interactions contributed an incremental amount to the prediction, preliminary hierarchical regression analyses were conducted. As a consequence, alcohol consumption on willingness $\times$ abstainer evaluation was incorporated into the men's model. Predictors were centred (Cohen, Cohen, West, \& Aiken, 2003) at each group's mean (Muthén \& Muthén, 1998-2007). Non-parametric resampling (with $N=1,500$ bootstrap samples) was used to provide accurate standard error estimates for inferential tests in view of non-normality (Neal \& Simons, 2007). Less than 3\% of the values were missing from the questionnaire data for sporadic items and one-third of the behavioural data was missing due to drop-outs. Because inappropriate handling of missing data may yield biased parameter estimates, missing data were treated by using the full-information maximum likelihood procedure (Allison, 2003; Schafer \& Graham, 2002).

Table I. Means, standard deviations, and $t$ statistics for sex differences in psychological and behavioural variables

\begin{tabular}{|c|c|c|c|c|c|}
\hline & \multicolumn{2}{|c|}{ Men } & \multicolumn{2}{|c|}{ Women } & \multirow[b]{2}{*}{$t$} \\
\hline & $M$ & $S D$ & $M$ & $S D$ & \\
\hline Intention & 4.80 & 2.19 & 3.58 & 2.10 & $4.92 * * *$ \\
\hline Attitude & 4.67 & 0.99 & 4.22 & 1.02 & $3.88 * * * *$ \\
\hline Subjective norm & 3.24 & 2.03 & 2.05 & 1.40 & $5.93 * * *$ \\
\hline Self-efficacy & 5.51 & $\mathrm{I} .34$ & 4.88 & $\mathrm{I} .47$ & $3.88 * * *$ \\
\hline Willingness & 4.04 & 1.91 & 3.25 & 1.66 & $3.81 * * *$ \\
\hline Actor evaluation & 58.85 & 18.74 & 57.37 & 19.48 & 0.67 \\
\hline Actor similarity & 4.62 & 1.59 & 4.09 & 1.55 & $2.92 * *$ \\
\hline Abstainer evaluation & 52.52 & 21.02 & 59.24 & 20.56 & $-2.80 * *$ \\
\hline Abstainer similarity & 3.15 & 1.59 & 3.73 & 1.53 & $-3.22 * *$ \\
\hline Past behaviour ${ }^{\mathrm{a}}$ & 7.96 & 6.43 & 4.83 & 4.54 & $4.89 * * *$ \\
\hline Alcohol consumption ${ }^{\mathrm{b}, \mathrm{c}}$ & 88.42 & 81.85 & 41.67 & 24.66 & $5.23 * * *$ \\
\hline
\end{tabular}

Note. $N=300$. Psychological variables range from I to 7 with the exception of the actor and abstainer evaluations ranging from extremely negative $(0)$ to extremely positive $(100)$; **p $<.01$; **** $<.00$ I (two-tailed). ${ }^{a}$ Frequency of drinking several glasses of alcohol in the past 4 weeks.

${ }^{\mathrm{b}}$ In grams of pure alcohol.

'Subsample $(N=171)$ of participants at Time 2 who spent an evening socializing and drank alcohol.

\section{Results}

\section{Preliminary analysis and descriptive findings}

Men and women differed significantly on almost all of the psychological and behavioural variables (see Table 1). On average, men had stronger intention, stronger willingness, a more positive attitude, a higher subjective norm, and higher self-efficacy regarding the consumption of several glasses of alcohol in one episode compared with women. Women had more positive abstainer evaluations and perceived themselves as more similar to this prototype and less similar to the actor prototype compared with men. With regard to past behaviour, men had consumed several glasses of alcohol more frequently than women. 
Both the actor and the abstainer prototypes were evaluated as more positive than negative on average (all means $>50$ on the $0-100$ scale, see Table 1 ). Men evaluated the actor prototype even more positively than the abstainer prototype, $t(152)=2.54$, $p<.05$, and perceived themselves to be more similar to the actor prototype compared with the abstainer prototype, $t(152)=6.66, p<.001$. These mean differences were not significant for women, neither regarding prototype evaluation, $t(146)=-.74$, $p=.46$, nor prototype similarity, $t(146)=1.38, p=.17$.

With respect to the consumption data, descriptive statistics refer to an eligible subsample $(N=171)$ of the persons attainable at Time 2 , namely 93 men and 78 women who spent a sociable evening and drank alcohol. Eight per cent of the men and twentythree per cent of the women $(N=31)$ of those attainable at Time 2 were engaged in a sociable episode and did not drink alcohol. Men consumed on average more than twice as many grams of pure alcohol $(88.42 \mathrm{~g}$, i.e., more than 7 drinks) as women. Twenty per cent of the women drank $\geq 4$ and fifty per cent of the men drank $\geq 5$ alcoholic drinks in a row and thus, would commonly be classified as binge drinkers (Wechsler, Dowdall et al., 1995). Men's drinking episodes lasted longer on average: while women drank for $3 \mathrm{~h}$ and $32 \mathrm{~min}(S D=1 \mathrm{~h} 49 \mathrm{~min})$, men drank for $4 \mathrm{~h}$ and $22 \mathrm{~min}$ $(S D=2 \mathrm{~h} 49 \mathrm{~min}), t(200)=2.32, p<.05$.

Only three of the theoretically expected relationships were non-significant: the correlation between abstainer evaluation and intention in both subsamples and the correlation between actor evaluation and intention in the female subsample (see Table 2).

\section{Multigroup analysis for the prediction of alcohol consumption}

Results of the multigroup path analysis of the whole model in which all paths were allowed to vary freely between groups are presented in Figure 1. Intercorrelations between exogenous variables, between past behaviour and intention and willingness, respectively, and between disturbances of intention and willingness were allowed. The model fit the data well, $\chi^{2}(17, N=300)=28.00, p=.05 ;$ CFI $=.98$, TLI $=.93$, RMSEA $=.07$, SRMR $=.02$. The model constrained to be equal across the two groups fit significantly worse, $\chi^{2}(67)=184.48, p<.001 ; \mathrm{CFI}=.78, \mathrm{TLI}=.80, \mathrm{RMSEA}=.11$, $\mathrm{SRMR}=.10$, according to the chi-squared difference test, $\Delta \chi^{2}(50)=156.48, p<.001$.

\section{Structural models for women}

The whole path model for women is given in Figure 1a. Intention and willingness were both predicted by subjective norm and self-efficacy. The more women perceived that their friends expected them to drink several glasses of alcohol during a social evening and the more they conceived of themselves as being able to do so, the more they intended to and were willing to behave accordingly. Explained variance for intention was $R^{2}=.28$ and for willingness was $R^{2}=.40$. The intentional path to behaviour was significant. In addition, self-efficacy showed a direct effect on alcohol consumption as predicted. Forty-one per cent of the variance in alcohol consumption was explained.

Paths of the TPB only model remained the same with respect to significance; coefficients varied only slightly in size. Subjective norm $(\beta=0.23, p<.01)$ and self-efficacy $(\beta=0.34, p<.001)$ influenced intention. In turn, self-efficacy $(\beta=0.21$, $p<.01)$ and intention $(\beta=0.45, p<.001)$ affected behaviour. Explained variance 


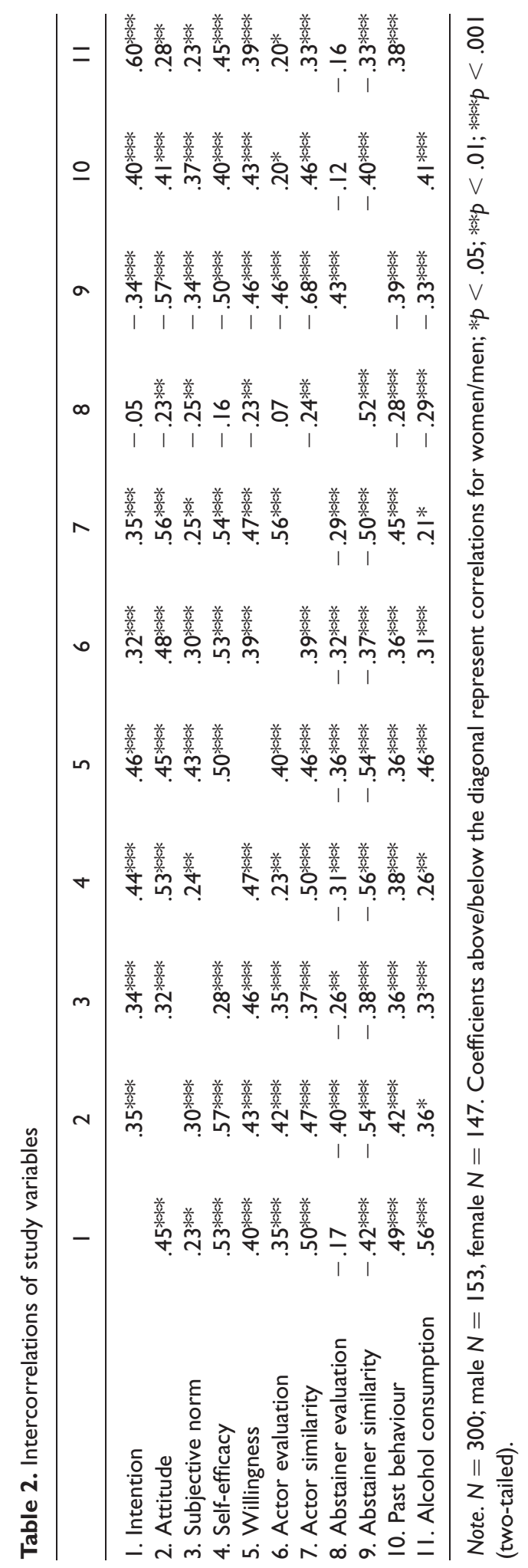


(a) Women

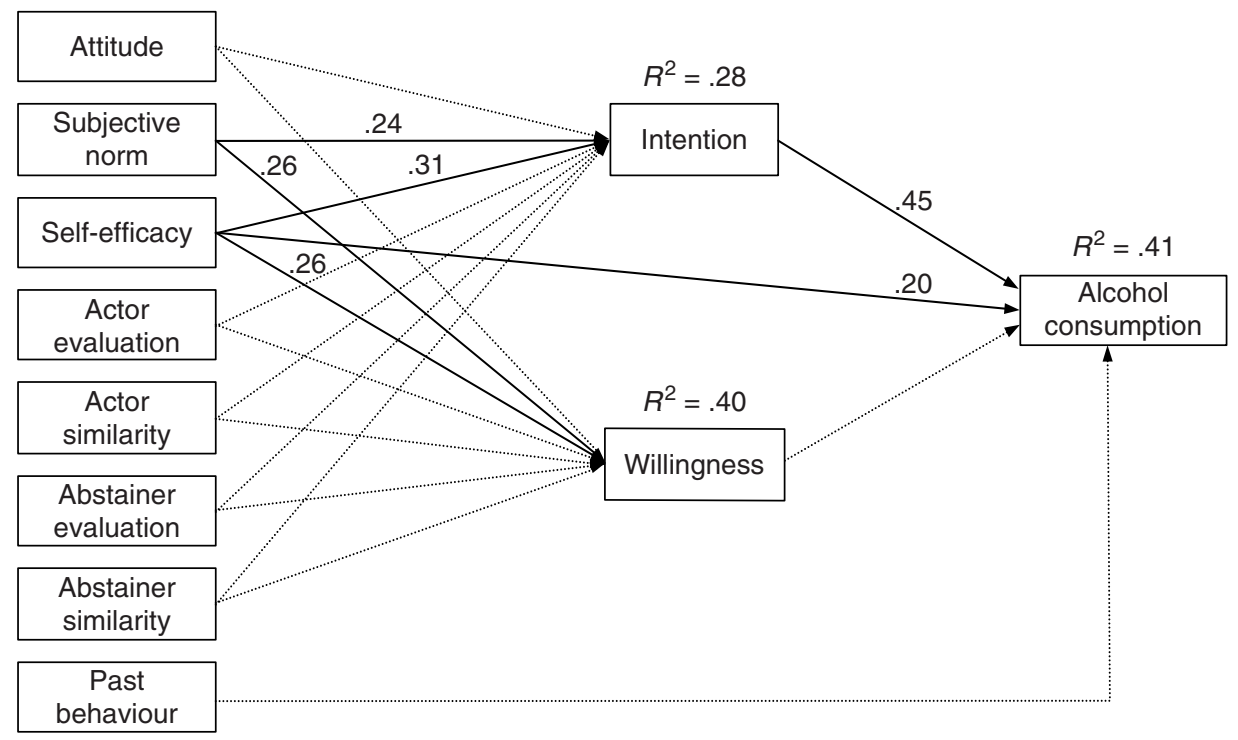

(b) Men

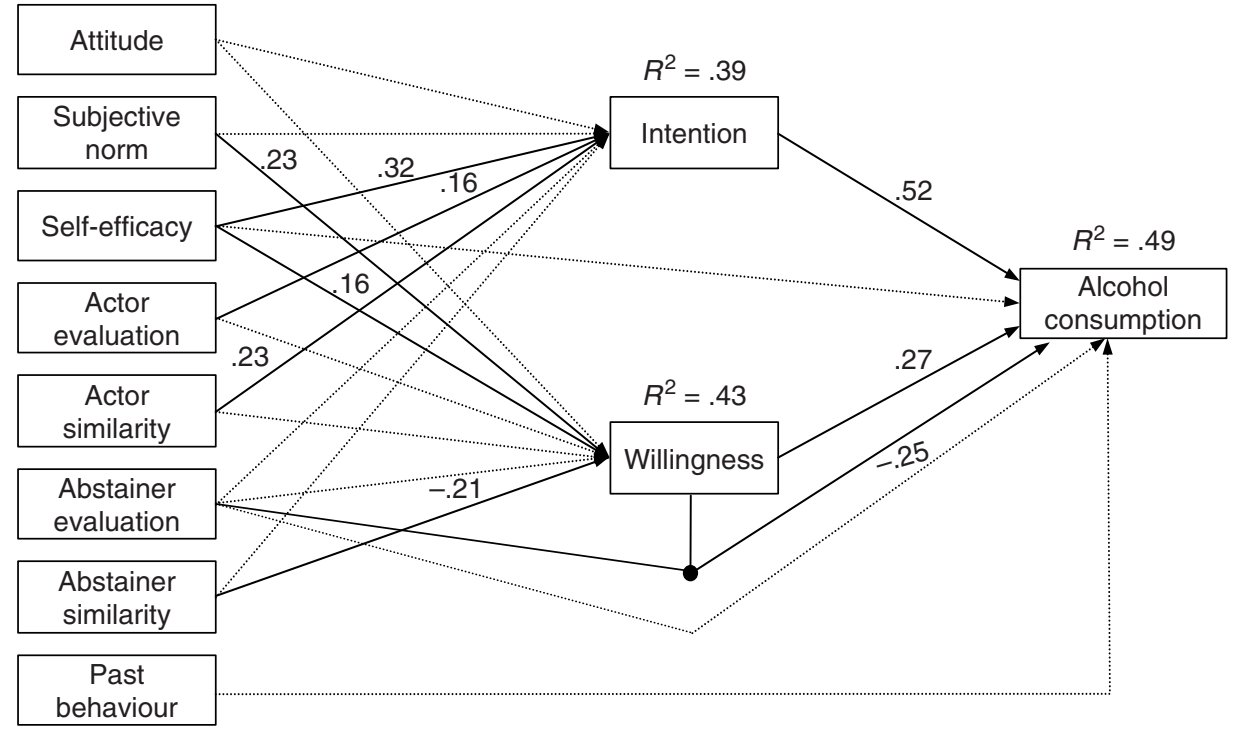

Figure I. Path model of the multigroup analysis $(N=300)$ : women versus men. Standardized path coefficients, statistically significant at $p<.05$. Dotted lines represent non-significant paths. Disturbances and correlations are not plotted. Model fit indices: $\chi^{2}(I 7, N=300)=28.00, p=.05$; $\mathrm{CFI}=.98, \mathrm{TLI}=.93, \mathrm{RMSEA}=.07, \mathrm{SRMR}=.02$.

for intention was $R^{2}=.27$ and for alcohol consumption was $R^{2}=.41$. Thus, augmentation with PWM variables did not increase the amount of explained variance in behaviour for women. Moreover, fixing the PWM paths in the full model to zero for women did not lead to a significantly worse fit, $\Delta \chi^{2}(9)=9.49, p=.39$. 
Structural models for men

The whole path model for men is given in Figure 1b. Self-efficacy, actor evaluation, and actor similarity significantly affected intention. The easier men perceived drinking several glasses of alcohol, the more positively they evaluated the actor prototype, and the more similarly they viewed themselves to this type of person, the more they intended to consume several alcoholic drinks during an evening of socializing. Explained variance for intention was $R^{2}=.39$. Willingness was determined by the subjective norm, self-efficacy, and the appraisal of being dissimilar to the abstainer image. $R^{2}=.43$ of the variance in willingness was explained. Both the intentional path and the willingness route were relevant for alcohol consumption in men. The willingness $\times$ abstainer evaluation also significantly predicted the outcome. The simple slopes of alcohol consumption on willingness at levels of abstainer evaluation (using scores above/below $M \pm 1 S D$, cf. Cohen et al., 2003) are depicted in Figure 2. Behavioural willingness contributed more strongly to alcohol consumption among those men with negative abstainer evaluations. Men who were high on willingness, but who had a positive image of the abstainer drank less heavily. Forty-nine per cent of the variance in alcohol consumption was explained.

One path of the TPB only model varied compared with the whole model for men: attitude affected intention $(\beta=0.22, p<.05)$. As before, self-efficacy $(\beta=0.39$, $p<.001)$ affected intention, and in turn, intention $(\beta=0.53, p<.001)$ predicted alcohol consumption. The explained variance for intention was $R^{2}=.32$ and for alcohol consumption was $R^{2}=.35$. Thus, augmentation with PWM variables increased the amount of explained variance in intention and behaviour by 7 and 14\%, respectively. Moreover, fixing the PWM paths in the full model to zero for men led to a significantly worse fit, $\Delta \chi^{2}(9)=43.24, p<.001$.

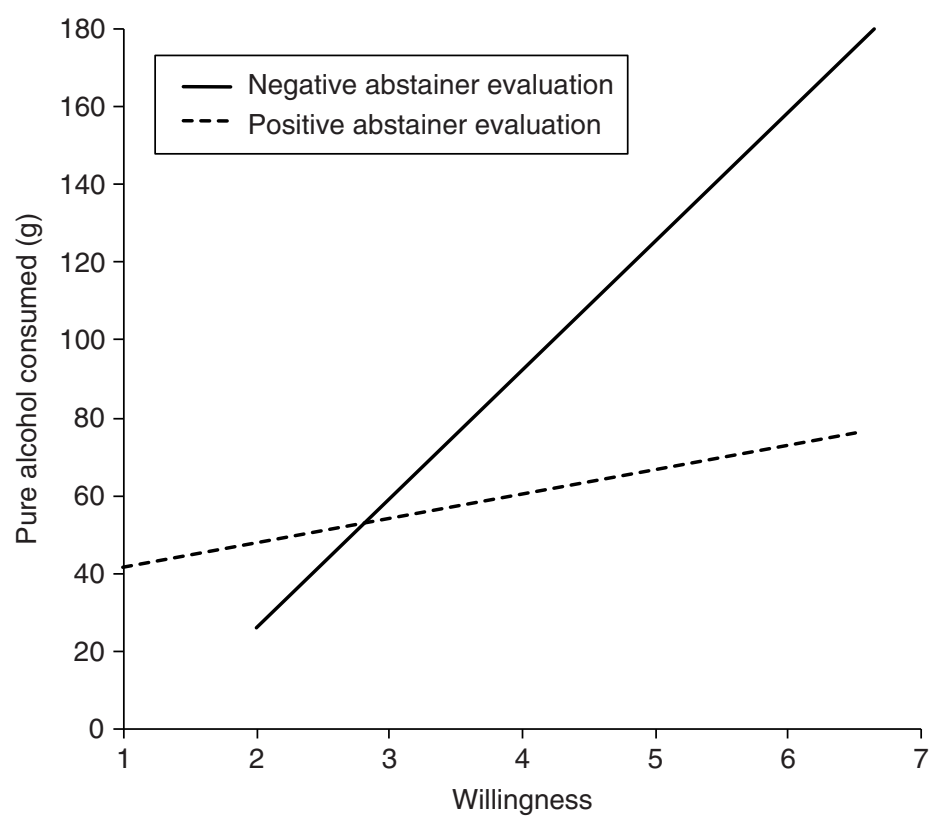

Figure 2. Alcohol consumption in men as a function of willingness at levels of abstainer evaluation (above/below $M \pm I S D$, i.e. scores $>73.36$ and $<31.04$ on the $0-100$ scale, cf. Cohen et al., 2003). 


\section{Discussion}

The present study examined the alcohol consumption of young adults in social contexts. A dual-process impact of predictors on the amount of pure alcohol consumed in grams was used by combining the TPB with the PWM. The main research question was whether willingness and the perceptions of actor and abstainer prototypes would successfully augment the TPB by contributing additional explained variance. To account for sex-differences in the study variables, multigroup path analyses were conducted.

The TPB was supported in the female subsample with one exception: attitude did not significantly predict intention (just as in the men's model). This may be the result of moderate intercorrelations between predictors (cf. the significant path of attitude on intention in the TPB only model in men). Self-efficacy consistently exerted its influence among women and men, except for the non-significant direct path of self-efficacy on behaviour in the male subsample. It may be astonishing that the confidence in being able to drink 'only' several $(>3)$ glasses of alcohol was an important predictor. PBC and self-efficacy were, however, frequently found to exert a strong effect on intention and behaviour in studies relating to drug use (including alcohol use) or other risk-related behaviours (Conner \& Sparks, 2005).

The subjective norm significantly predicted both intention and willingness in the female subsample. In the male subsample, subjective norm failed to exert an influence on intention, whereas actor prototype perception represented a significant normative influence on intention. Thus, although the relative importance of TPB components is expected to vary across behaviours (Ajzen, 1991), social influences appear to be quite important with regard to alcohol consumption. Studies that failed to detect effects of the subjective norm on the intention to drink alcohol - even when using multi-item scales with good reliability (e.g., Collins \& Carey, 2007; Norman et al., 2007) - presumably suffered from an insufficient conceptualization of social influence (Conner \& Sparks, 2005). Moreover, the path of actor evaluation to intention (i.e., the reasoned pathway) adds to the evidence that risk images may serve as goals (Rivis et al., 2006).

Perception of the abstainer prototype was involved with the social reaction pathway. Dissimilarity with the abstainer image facilitated the willingness to drink for men. The abstainer prototype should be even more salient than the actor prototype as it is an exception to the norm for this age group: in the context of a high actor norm, individuals would grab attention for not drinking alcohol, and would suffer the consequence of the abstainer image's attributes sticking to their own identity (cf. Blanton \& Christie, 2003). If these attributes were perceived as negative, people should deviate from abstaining in order to maintain a positive sense of self. The finding that willingness led to heavy alcohol consumption particularly among those men who evaluated the abstainer prototype negatively (see Figure 2) supports this assumption.

Internalization of the traditional masculine image may be reflected in these results (Lemle \& Mishkind, 1989; McCreary, Newcomb, \& Sadava, 1999). There is no need, however, that men actually have more traditional attitudes: a different mechanism may be that they seek to create the impression to conform to the traditional masculine image. This may be of importance for them, because of the precarious nature of manhood relative to womanhood (Vandello, Bosson, Cohen, Burnaford, \& Weaver, 2008). People view manhood as a tenuous state and thus, 'men may prove themselves with informal and sometimes harmful - demonstrations of masculinity' (Vandello et al., 2008, p. 1325). Performing health-risk behaviours like heavy drinking may be regarded as a means of affirming their masculinity (Courtenay, 2000). It may as well be viewed as unmanly to 
stop drinking in a given situation: 'To "drink like a man" one must. . .', for example, “"hold his liquor," i.e., drink as much as possible without appearing out of control' (Lemle \& Mishkind, 1989, p. 215). In line with this statement, male college students reported greater embarrassment when expressing drinking-related concerns than their female counterparts (Suls \& Green, 2003).

Prototype perception was not relevant in the women's model: evaluation of the actor image did not affect intention and dissimilarity to the abstainer image did not affect willingness in contrast to the men's model. The interaction of willingness $\times$ abstainer evaluation was also not relevant for women; they may feel less pressure to avoid abstainer attributes in social drinking situations than men. Women evaluated the abstainer prototype accordingly as more positive and more similar to the self in contrast to men on average.

Gender differences in perception and impact of the prototypes on alcohol consumption probably resulted from traditional gender roles. Whereas alcohol use is socially encouraged for males as it is traditionally associated with attributes of masculinity like strength and willingness to take risks (see above, Lemle \& Mishkind, 1989), women's primary responsibilities for child care may have contributed to social disapproval of heavy drinking in females (e.g., Waldron, 1988, 1997). They probably had a stronger need to control their drinking if they were traditionally expected to keep to low levels of alcohol intake. The current study indicates that - whereas social reactive influences additionally precede alcohol consumption in men - women's drinking behaviour is solely premeditated. An alternative explanation refers to the measurement of willingness: do women not drink spontaneously, or do they only not overdrink in reaction to a given situation? At least, they do not tend to overdrink (in contrast to men) - maybe in part because their alcohol consumption is limited due to premeditation in the reasoned-action process.

The moderating effect of gender with regard to alcohol consumption turned out to be meaningful among the young German adults in this study. ${ }^{3}$ Pervasive sex differences emerged in some of the other studies investigating alcohol consumption in young people (e.g., Conner et al., 1999; Norman et al., 1998; Spijkerman et al., 2004). However, the relationships might be more similar for both sexes, for example, in the USA, where gender differences in measures of alcohol consumption are decreasing in younger age cohorts (Keyes, Grant, \& Hasin, 2008), or in the UK, where drinking behaviour among young people has converged due to an increase in girls' and women's drinking (Plant, 2008).

Evaluation and the impact of the actor and abstainer prototypes turned out to be somewhat different than suggested by most of the studies with adolescents. Gerrard et al. (2002) found that adolescents perceived the abstainer image as somewhat more positive (and operating via contemplation) than the actor prototype (which influenced behaviour through willingness). The reverse was true in this study: the actor image, which men regarded as more positive and more similar to the self than the abstainer image, exerted its impact via intention; the abstainer image, which they

\footnotetext{
${ }^{3}$ We do not assume that underlying psychological processes are different for men and women in principle. Results according to the factor structure of gender role dimensions indicate that men and women internalize aspects of gender roles in the same way (McCreary, Newcomb, \& Sadava, 1998). Nevertheless, it was shown that men were more likely than women to link aspects of their gender role with alcohol consumption (McCreary et al., 1999), which is plausible given gender-specific drinking norms by tradition. Thus, models of alcohol consumption do not have to be equal for men and women even if assuming a basically similar psychological make-up for both sexes.
} 
viewed as comparatively negative and less similar to the self, affected behaviour in association with willingness.

The effect of intention outweighed the effect of willingness on alcohol consumption among the young men. This is in line with the assumption that the proximal antecedents of behaviour shift over the developmental course from childhood to adulthood: willingness becomes less predictive with increased experience with the behaviour whereas intention becomes a better predictor of that behaviour (cf. Gerrard et al., 2008). Although reasoned action outweighed social reaction in our study with young adults, social reaction played an important role for males by explaining an additional $13 \%$ of their alcohol consumption.

\section{Implications for interventions}

Intervention strategies should consider differences between men and women in their psychological antecedents of alcohol consumption in social contexts. Women seemed to be protected to some extent, for example, by their lower subjective norm with respect to alcohol consumption. The results imply that intervention efforts should especially focus on men. Prototypes appear to be promising targets. It was demonstrated, for example, that prototype manipulation in the form of systematic contemplation of the typical exerciser and the typical non-exerciser increased exercise behaviour over a 4-week interval for those high in social comparison tendency (Ouellette, Hessling, Gibbons, Reis-Bergan, \& Gerrard, 2005). Thus, contemplation about prototypes related to alcohol consumption might represent a fruitful strategy for reducing heavy drinking in men. For example, negative attributes of the heavy drinker prototype could be accentuated in order to increase its distance to the person's self and resulting in the intention to drink less. Increasing the attractiveness of the non-drinker prototype, or more realistically, of moderate drinker prototypes, on the other hand, could decrease the willingness to drink heavily. To effectively inhibit alcohol consumption even in the presence of tempting risk situations, however, profound alterations of the images would probably have to take place. Maybe the assignment of celebrities or the presentation of prototypical examples with more similarity to the target population could be useful to establish images to reduce heavy drinking. Recent work indeed highlights the impact of alcohol depictions in movies and offers insight into the processes accounting for their influence on alcohol use of adolescents (Dal Cin et al., 2009): the effect of exposure to movie portrayals of alcohol use on alcohol consumption was mediated, for example, by alcohol prototypes via willingness. It can be expected that different portrayals of alcohol consumption (e.g., heavy drinking as less positively and without reinforcement of the actor, or light drinking as less negative and with reinforcement of the actor) might change subsequent prototypes and willingness, and in turn actual alcohol consumption. In all these approaches, if targeting men, it might be recommended to pay attention to the appearance of such light or moderate drinker examples as still manly.

\section{Limitations and future directions}

There are some limitations of our study that deserve attention. With regard to operationalization there is, first, the problem that intention and subjective norm were assessed with only one item, which makes it impossible to determine their reliabilities. Nevertheless, these contents are clear cut, and single items are as informative as 
multi-item scales when they are easy to understand (cf. Helgeson, 1992). Future research may benefit, however, from using multiple-item measures. Second, the frequency of consuming several glasses of alcohol in the past 4 weeks in relation to the amount of alcohol consumed on one occasion is only an approximation for past behaviour. Without compatibility, the relation of past and future behaviour is likely to be underestimated. However, applying identical scales has been criticized for resulting in overly high correlations (Ajzen, 1991, 2002b). It is uncertain whether past behaviour fully accounted for factors associated with the behaviour in question and served as a test of the models' sufficiency in this study.

Another limitation of this study is the measurement of alcohol consumption by selfreports. Some participants may have reported their alcohol consumption as being less than actually was the case; they may also have given different ratings in the questionnaire in contrast to people who did not underreport their consumption. This might have led to biased relationships between responses at Time 1 and Time 2 . Nevertheless, self-reports of health-risk behaviour are reasonably valid and reliable and can be optimized by careful data collection (Brener, Billy, \& Grady, 2003; Del Boca \& Darkes, 2003). Confidentiality was guaranteed, and the context of data collection was hardly threatening or associated with any consequences for the individual, providing little incentive to respond dishonestly. To further enhance the accuracy of the data, we chose a short-time interval to reduce errors due to poor recall, and asked participants to estimate the specific amount of each of the different alcoholic beverages consumed, instead of using vaguely defined standard drink units.

A further problem is that the assessment of social-cognitive variables at Time 1 may have influenced future behaviour explicitly or implicitly and thus, may have led to inflated relations between predictors and the outcome. For example, expressing a certain intention may explicitly have led to the felt commitment to drink correspondingly to that intention later that evening or to report having drunk correspondingly to maintain consistency. Similarly, it cannot be ruled out that the request to estimate ones' intention stimulated processes of elaboration upon the how, when, and where of drinking several glasses of alcohol that evening. The Time 1 questionnaire may also have had an implicit priming effect on drinking behaviour: having previously thought about factors related to alcohol consumption may have made alcohol-related cues in the drinking situation more salient. This effect could have been especially strong for prototype perception as questions about the actor and the abstainer prototype are rather unusual and may have been especially salient. Nevertheless, participants were not forced to decide between two categories for each item in the Time 1 questionnaire, but had to indicate a certain degree on a continuum, which gives more latitude to deviate without feeling inconsistent. Moreover, they were not requested to specify the exact number of drinks they intended to consume offering a certain range regarding the amount consumed. After all, correlations between socialcognitive variables and alcohol consumption indicate no deterministic relations, but imply variation in that many people were not behaving in accordance with their previously given ratings.

A final drawback is the limited generalizability of our findings. The sample consisted of emergent young adults with a high percentage of university students. University students and non-students differed on two of the variables studied. Students regarded themselves as less similar to the abstainer prototype, $t(298)=-2.29, p<.05$, and evaluated the actor prototype more positively, $t(298)=2.03, p<.05$. Women were not 
more likely to be non-students. Generalizations to the population of emergent young adults, however, are limited to the highly educated strata.

Despite the aforementioned limitations, this study is the first to apply variables unique to the PWM together with the TPB to alcohol consumption in emerging adulthood. By testing a dual-mode model, the current study demonstrated the value of the willingness-based social reaction path next to the intentional reasoned action path for understanding and predicting alcohol consumption in social contexts. Further strengths of the study were the inclusion of abstainer prototype variables next to the more commonly investigated actor prototype variables and the detailed assessment of drinking behaviour. For a statistically appropriate representation of the theoretical model, we applied path analysis by simultaneously testing the model as a whole, instead of using a set of multiple regression analyses. Furthermore, to obtain unbiased standard errors, we made use of non-parametric bootstrapping.

Abstaining from alcohol consumption at social events is comparatively uncommon among young adults, and it may be promising to further investigate the counternormative influence of the probably more salient abstainer prototype in this age group in addition to the actor prototype (cf. Blanton \& Christie, 2003). Also worthy of further study is the application of the dual-mode impact of predictors to young adults especially the role of willingness, which was initially considered to be important for risk behaviour in children and adolescents (Gerrard et al., 2008). In this regard, the moderating role of gender was essential. This may be important for interventions and future research - even in the presence of increasing gender convergence in alcohol consumption in some countries (Keyes et al., 2008; Plant, Miller, \& Plant, 2005) as women's increased drinking does not necessarily imply gender equality, and drinking motives may remain different for men and women (Young, Morales, McCabe, Boyd, \& D'Arcy, 2005).

\section{Acknowledgements}

We thank Frederick X. Gibbons for his helpful comments on an earlier draft of this article.

\section{References}

Ajzen, I. (1991). The theory of planned behavior. Organizational Behavior and Human Decision Processes, 50(2), 179-211.

Ajzen, I. (2002a). Perceived behavioral control, self-efficacy, locus of control, and the theory of planned behavior. Journal of Applied Social Psychology, 32(4), 665-683.

Ajzen, I. (2002b). Residual effects of past on later behavior: Habituation and reasoned action perspectives. Personality and Social Psychology Review, 6(2), 107-122.

Ajzen, I. (2006, January). Constructing a TPB questionnaire: Conceptual and methodological considerations. Retrieved from http://people.umass.edu/aizen/tpb.html

Allison, P. D. (2003). Missing data techniques for structural equation modeling. Journal of Abnormal Psychology, 112(4), 545-557.

Armitage, C. J., \& Conner, M. (2001). Efficacy of the theory of planned behaviour: A meta-analytic review. British Journal of Social Psychology, 40(4), 471-499. doi:10.1348/014466601164939

Armitage, C. J., Conner, M., Loach, J., \& Willetts, D. (1999). Different perceptions of control: Applying an extended theory of planned behavior to legal and illegal drug use. Basic and Applied Social Psychology, 21(4), 301-316. 
Bailer, J., Schwarz, D., Witthoeft, M., Stuebinger, C., \& Rist, F. (2008). Prävalenz psychischer Syndrome bei Studierenden einer deutschen Universität [Prevalence of mental disorders among college students at a German university]. Psychotherapie, Psychosomatik, Medizinische Psychologie, 58, 423-429.

Bandura, A. (1977). Self-efficacy: Toward a unifying theory of behavioral change. Psychological Review, 84(2), 191-215.

Blanton, H., \& Christie, C. (2003). Deviance regulation: A theory of action and identity. Review of General Psychology, 7(2), 115-149.

Brener, N. D., Billy, J. O., \& Grady, W. R. (2003). Assessment of factors affecting the validity of selfreported health-risk behavior among adolescents: Evidence from the scientific literature. Journal of Adolescent Health, 33(6), 436-457.

British Medical Association (1995). Alcohol: Guidelines on sensible drinking. London: Author.

Bundeszentrale für gesundheitliche Aufklaerung (2004). Die Drogenaffinitaet Jugendlicher in der Bundesrepublik Deutschland 2004. Teilband Alkohol. Köln: Bundeszentrale für gesundheitliche Aufklärung.

Cantor, N., Mischel, W., \& Schwartz, J. C. (1982). A prototype analysis of psychological situations. Cognitive Psychology, 14(1), 45-77.

Chassin, L. A., Tetzloff, C., \& Hershey, M. (1985). Self-image and social-image factors in adolescent alcohol use. Journal of Studies on Alcohol, 46(1), 39-47.

Cohen, J., Cohen, P., West, S. G., \& Aiken, L. S. (2003). Applied multiple regression/correlation analysis for the behavioral sciences (3rd ed.). Mahwah, NJ: Erlbaum.

Collins, S. E., \& Carey, K. B. (2007). The theory of planned behavior as a model of heavy episodic drinking among college students. Psychology of Addictive Behaviors, 21(4), 498-507.

Conner, M., \& Sparks, P. (2005). Theory of planned behaviour and health behaviour. In M. Conner \& P. Norman (Eds.), Predicting bealth behaviour (pp.170-222). Buckingham: Open University Press.

Conner, M., Warren, R., Close, S., \& Sparks, P. (1999). Alcohol consumption and the theory of planned behavior: An examination of the cognitive mediation of past behavior. Journal of Applied Social Psychology, 29(8), 1676-1704.

Corrao, G., Bagnardi, V., Zambon, A., \& La Vecchia, C. (2004). A meta-analysis of alcohol consumption and the risk of 15 diseases. Preventive Medicine: An International Journal Devoted to Practice and Theory, 38(5), 613-619.

Courtenay, W. H. (2000). Constructions of masculinity and their influence on men's well-being: A theory of gender and health. Social Science and Medicine, 50(10), 1385-1401.

Dal Cin, S., Worth, K. A., Gerrard, M., Gibbons, F. X., Stoolmiller, M., Wills, T. A., et al. (2009). Watching and drinking: Expectancies, prototypes, and friends' alcohol use mediate the effect of exposure to alcohol use in movies on adolescent drinking. Health Psychology, 28(4), 473-483.

Dantzer, C., Wardle, J., Fuller, R., Pampalone, S. Z., \& Steptoe, A. (2006). International study of heavy drinking: Attitudes and sociodemographic factors in university students. Journal of American College Health, 55(2), 83-89.

Del Boca, F., \& Darkes, J. (2003). The validity of self-reports of alcohol consumption: State of the science and challenges for research. Addiction, 98, 1-12.

Dunning, D., Perie, M., \& Story, A. L. (1991). Self-serving prototypes of social categories. Journal of Personality and Social Psychology, 61(6), 957-968.

Fazio, R. H. (1990). Multiple processes by which attitudes guide behavior: The MODE model as an integrative framework. In M. P. Zanna (Ed.), Advances in experimental social psychology (Vol. 23, pp. 75-109). San Diego, CA: Academic.

Fishbein, M., Triandis, H. C., Kanfer, F. H., Becker, M., Middlestadt, S. E., \& Eichler, A. (2001). Factors influencing behavior and behavior change. In A. Baum, T. A. Revenson, \& J. E. Singer (Eds.), Handbook of health psychology (pp.3-17). Mahwah, NJ: Erlbaum. 
Francis, J. J., Eccles, M. P., Johnston, M., Walker, A., Grimshaw, J., Foy, R., et al. (2004). Constructing questionnaires based on the theory of planned behavior. A manual for health service researchers. Newcastle upon Tyne: Centre for Health Services Research.

Gerrard, M., Gibbons, F. X., Brody, G. H., Murry, V. M., Cleveland, M. J., \& Wills, T. A. (2006). A theory-based dual-focus alcohol intervention for preadolescents: The strong African American families program. Psychology of Addictive Behaviors, 20(2), 185-195.

Gerrard, M., Gibbons, F. X., Houlihan, A. E., Stock, M. L., \& Pomery, E. A. (2008). A dual-process approach to health risk decision making: The prototype willingness model. Developmental Review, 28(1), 29-61.

Gerrard, M., Gibbons, F. X., Reis-Bergan, M., Trudeau, L., Vande Lune, L. S., \& Buunk, B. (2002). Inhibitory effects of drinker and nondrinker prototypes on adolescent alcohol consumption. Health Psychology, 21(6), 601-609.

Gibbons, F. X., \& Gerrard, M. (1995). Predicting young adults' health risk behavior. Journal of Personality and Social Psychology, 69(3), 505-517.

Gibbons, F. X., \& Gerrard, M. (1997). Health images and their effects on health behavior. In B. Buunk \& F. X. Gibbons (Eds.), Health, coping and well-being: Perspectives from social comparison theory (pp. 63-94). Mahwah, NJ: Erlbaum.

Gibbons, F. X., Gerrard, M., Blanton, H., \& Russell, D. W. (1998). Reasoned action and social reaction: Willingness and intention as independent predictors of health risk. Journal of Personality and Social Psychology, 74(5), 1164-1180.

Gibbons, F. X., Gerrard, M., \& Boney-McCoy, S. (1995). Prototype perception predicts (lack of) pregnancy prevention. Personality and Social Psychology Bulletin, 21(1), 85-93.

Gibbons, F. X., Gerrard, M., \& Lane, D. J. (2003). A social-reaction model of adolescent health risk. In J. M. Suls \& K. A. Wallston (Eds.), Social psychological foundations of health and illness (pp. 107-136). Oxford: Backwell.

Gibbons, F. X., Gerrard, M., Lune, L. S. V., Wills, T. A., Brody, G., \& Conger, R. D. (2004). Context and cognitions: Environmental risk, social influence, and adolescent substance use. Personality and Social Psychology Bulletin, 30(8), 1048-1061.

Gibbons, F. X., Gerrard, M., Ouelette, J., \& Burzette, B. (1998). Cognitive antecedents to adolescent health risk: Discriminating between behavioral intention and behavioral willingness. Psychology and Health, 13, 319-340.

Gill, J. S. (2002). Reported levels of alcohol consumption and binge drinking within the UK undergraduate student population over the last 25 years. Alcohol and Alcoholism, 37(2), 109-120.

Gmel, G., Rehm, J., \& Kuntsche, E. (2003). Binge drinking in Europe: Definitions, epidemiology, and consequences. Sucht: Zeitschrift fuer Wissenschaft und Praxis, 49(2), 105-116.

Godin, G., \& Kok, G. (1996). The theory of planned behavior: A review of its applications to health-related behaviors. American Journal of Health Promotion, 11(2), 87-98.

Haddock, G., \& Zanna, M. P. (1994). Preferring 'housewives' to 'feminists': Categorization and the favorability of attitudes toward women. Psychology of Women Quarterly, 18(1), 25-52.

Helgeson, V. S. (1992). Moderators of the relation between perceived control and adjustment to chronic illness. Journal of Personality and Social Psychology, 63(4), 656-666.

Hingson, R. W., Heeren, T., Zakocs, R. C., Kopstein, A., \& Wechsler, H. (2002). Magnitude of alcohol-related mortality and morbidity among US college students ages 18-24. Journal of Studies on Alcohol, 63(2), 136-144.

Johnston, K. L., \& White, K. M. (2003). Binge-drinking: A test of the role of group norms in the theory of planned behaviour. Psychology and Health, 18(1), 63-77.

Keyes, K. M., Grant, B. F., \& Hasin, D. S. (2008). Evidence for a closing gender gap in alcohol use, abuse, and dependence in the United States population. Drug and Alcohol Dependence, 93(1), 21-29.

Kraus, L., \& Augustin, R. (2001). Measuring alcohol consumption and alcohol-related problems: Comparison of responses from self-administered questionnaires and telephone interviews. Addiction, 96(3), 459-471. 
Lemle, R., \& Mishkind, M. E. (1989). Alcohol and masculinity. Journal of Substance Abuse Treatment, 6(4), 213-222.

McCreary, D. R., Newcomb, M. D., \& Sadava, S. W. (1998). Dimensions of the male gender role: A confirmatory analysis in men and women. Sex Roles, 39(1), 81-95.

McCreary, D. R., Newcomb, M. D., \& Sadava, S. W. (1999). The male role, alcohol use, and alcohol problems: A structural modeling examination in adult women and men. Journal of Counseling Psychology, 46(1), 109-124.

McMillan, B., \& Conner, M. (2003). Using the theory of planned behaviour to understand alcohol and tobacco use in students. Psychology, Health and Medicine, 8(3), 317-328.

Muthén, L. K., \& Muthén, B. O. (1998-2007). Mplus user's guide (5th ed.). Los Angeles, CA: Muthén \& Muthén.

Muthén, L. K., \& Muthén, B. O. (2008) Mplus version 5.2 [Computer Software].

Naimi, T. S., Brewer, R. D., Mokdad, A., Denny, C., Serdula, M. K., \& Marks, J. S. (2003). Binge drinking among US adults. Journal of the American Medical Association, 289(1), 70-75.

Neal, D. J., \& Simons, J. S. (2007). Inference in regression models of heavily skewed alcohol use data: A comparison of ordinary least squares, generalized linear models, and bootstrap resampling. Psychology of Addictive Behaviors, 21(4), 441-452.

Niedenthal, P. M., Cantor, N., \& Kihlstrom, J. F. (1985). Prototype matching: A strategy for social decision making. Journal of Personality and Social Psychology, 48(3), 575-584.

Norman, P., Armitage, C. J., \& Quigley, C. (2007). The theory of planned behavior and binge drinking: Assessing the impact of binge drinker prototypes. Addictive Behaviors, 32(9), $1753-1768$.

Norman, P., Bennett, P., \& Lewis, H. (1998). Understanding binge drinking among young people: An application of the theory of planned behaviour. Health Education Research, 13(2), 163-169.

Norman, P., \& Conner, M. (2006). The theory of planned behaviour and binge drinking: Assessing the moderating role of past behaviour within the theory of planned behaviour. British Journal of Health Psychology, 11(1), 55-70. doi:10.1348/135910705X43741

Ouellette, J. A., Gerrard, M., Gibbons, F. X., \& Reis-Bergan, M. (1999). Parents, peers, and prototypes: Antecedents of adolescent alcohol expectancies, alcohol consumption, and alcohol-related life problems in rural youth. Psychology of Addictive Behaviors, 13(3), 183-197.

Ouellette, J. A., Hessling, R., Gibbons, F. X., Reis-Bergan, M., \& Gerrard, M. (2005). Using images to increase exercise behavior: Prototypes versus possible selves. Personality and Social Psychology Bulletin, 31(5), 610-620.

Plant, M. L. (2008). The role of alcohol in women's lives: A review of issues and responses. Journal of Substance Use, 13(3), 155-191.

Plant, M. L., Miller, P., \& Plant, M. A. (2005). The relationship between alcohol consumption and problem behaviours: Gender differences among British adults. Journal of Substance Use, 10(1), 22-30.

Rivis, A., Sheeran, P., \& Armitage, C. J. (2006). Augmenting the theory of planned behaviour with the prototype/willingness model: Predictive validity of actor versus abstainer prototypes for adolescents' health-protective and health-risk intentions. British Journal of Health Psychology, 11, 483-500. doi:10.1348/135910705X70327

Robert Koch Institut (2003). Bundes-Gesundheitssurvey: Alkohol. Berlin: Author.

Rosch, E., \& Mervis, C. B. (1975). Family resemblances: Studies in the internal structure of categories. Cognitive Psychology, 7(4), 573-605.

Schafer, J. L., \& Graham, J. W. (2002). Missing data: Our view of the state of the art. Psychological Methods, 7(2), 147-177.

Spijkerman, R., van den Eijnden, R. J. J. M., Overbeek, G., \& Engels, R. C. M. E. (2007). The impact of peer and parental norms and behavior on adolescent drinking: The role of drinker prototypes. Psychology and Health, 22(1), 7-29. 
Spijkerman, R., van den Eijnden, R. J. J. M., Vitale, S., \& Engels, R. C. M. E. (2004). Explaining adolescents' smoking and drinking behavior: The concept of smoker and drinker prototypes in relation to variables of the theory of planned behavior. Addictive Behaviors, 29(8), 1615-1622.

Stahre, M., Naimi, T., Brewer, R., \& Holt, J. (2006). Measuring average alcohol consumption: The impact of including binge drinks in quantity-frequency calculations. Addiction, 101(12), 1711-1718.

Suls, J., \& Green, P. (2003). Pluralistic ignorance and college student perceptions of genderspecific alcohol norms. Health Psychology, 22(5), 479-486.

Trafimow, D., Sheeran, P., Conner, M., \& Finlay, K. A. (2002). Evidence that perceived behavioural control is a multidimensional construct: Perceived control and perceived difficulty. British Journal of Social Psychology, 41(1), 101-121. doi:10.1348/0144666602165081

Vandello, J. A., Bosson, J. K., Cohen, D., Burnaford, R. M., \& Weaver, J. R. (2008). Precarious manhood. Journal of Personality and Social Psychology, 95(6), 1325-1339.

Waldron, I. (1988). Gender and health-related behavior. In D. S. Gochman (Ed.), Health behavior: Emerging research perspectives (pp. 193-208). New York: Plenum Press.

Waldron, I. (1997). Changing gender roles and gender differences in health behavior. In D. S. Gochman (Ed.), Handbook of bealth behavior research 1: Personal and social determinants (pp. 303-328). New York: Plenum Press.

Wall, A.-M., Hinson, R. E., \& McKee, S. A. (1998). Alcohol outcome expectancies, attitudes toward drinking and the theory of planned behavior. Journal of Studies on Alcohol, 59(4), 409-419.

Wechsler, H., Dowdall, G. W., Davenport, A., \& Rimm, E. B. (1995). A gender-specific measure of binge drinking among college students. American Journal of Public Health, 85(7), 982-985.

Wechsler, H., Lee, J. E., Kuo, M., \& Lee, H. (2000). College binge drinking in the 1990s: A continuing problem: Results of the Harvard School of Public Health 1999 college alcohol study. Journal of American College Health, 48(5), 199-210.

Wechsler, H., Moeykens, B., Davenport, A., \& Castillo, S. (1995). The adverse impact of heavy episodic drinkers on other college students. Journal of Studies on Alcohol, 56(6), 628-634.

Young, A. M., Morales, M., McCabe, S. E., Boyd, C. J., \& D'Arcy, H. (2005). Drinking like a guy: Frequent binge drinking among undergraduate women. Substance Use and Misuse, 40(2), 241-267.

Received 3 March 2009; revised version received 9 September 2009 